\title{
Article
}

\section{Barriers and facilitators to a criminal justice tobacco control coordinator: an innovative approach to supporting smoking cessation among offenders}

Eadie, Douglas, MacAskill, Susan, McKell, Jennifer and Baybutt, Michelle

Available at http://clok.uclan.ac.uk/6377/

Eadie, Douglas, MacAskill, Susan, McKell, Jennifer and Baybutt, Michelle ORCID: 0000-0002-3201-7021 (2012) Barriers and facilitators to a criminal justice tobacco control coordinator: an innovative approach to supporting smoking cessation among offenders. Addiction, 107 (Sup.S2). pp. 26-38. ISSN $0965-2140$

It is advisable to refer to the publisher's version if you intend to cite from the work. http://dx.doi.org/10.1111/j.1360-0443.2012.04083.x

For more information about UCLan's research in this area go to http://www.uclan.ac.uk/researchgroups/ and search for < name of research Group>.

For information about Research generally at UCLan please go to http://www.uclan.ac.uk/research/

All outputs in CLoK are protected by Intellectual Property Rights law, including Copyright law. Copyright, IPR and Moral Rights for the works on this site are retained by the individual authors and/or other copyright owners. Terms and conditions for use of this material are defined in the policies page. 


\title{
Barriers and facilitators to a Criminal Justice Tobacco Control Coordinator: an innovative approach to supporting cessation among offenders
}

\author{
Douglas Eadie ${ }^{1}$, Susan MacAskill ${ }^{1}$, Jennifer McKell ${ }^{1}$ and Michelle Baybutt ${ }^{2}$
}

\footnotetext{
${ }^{1}$ Institute for Social Marketing, University of Stirling and Open University, Stirling, FK9 4LA

${ }^{2}$ Healthy Settings Unit, School of Health, Brook 318, Preston, Lancashire PR1 2HE
}

Running Head: Facilitating change: Using a coordinator to supporting cessation among offenders

Word Count: 3,946 (excluding title, abstract, references, acknowledgements, participant quotes, tables, boxes and figures)

Declaration of Interest: Michelle Baybutt acted as the intervention manager for the project under evaluation. The remaining authors have no interests to declare 


\section{ABSTRACT}

\section{Aims}

To examine the barriers and facilitators of a regional tobacco control coordinator working across criminal justice and public health systems for 12 months from December 2010.

\section{Design}

A mixed methods case study approach utilising in-depth interviews, project reports and observation of advisory meetings.

\section{Setting}

The coordinator worked with prisons, probation and police custody, targeting cessation support to offenders where there are high levels of social disadvantage and smoking.

\section{Participants}

Interviews $(n=34)$ at different stages of project development with the coordinator, project advisors and local stakeholders from criminal justice and public health.

\section{Measurements}

Analysis of project facilitators and barriers, and the coordinator role from different perspectives.

\section{Findings}

Readiness to change was a critical predictor of engagement with the coordinator role. The coordinator enhanced cessation service delivery in individual prisons where there is a requirement and infrastructure in place to provide such services. In police custody, where there is no central guidance and no prexisting requirements, efforts to establish smoking cessation on the local settings 
agenda proved ineffective. In probation settings, the coordinator documented examples of good practice in the delivery of cessation services and supported brief intervention training. Variability in engagement limited the projects ability to create joined up working across criminal justice settings.

\section{Conclusions}

The coordinator was able to effect change within prisons, but not across the criminal justice pathway where a more strategic approach is required. This would necessitate a higher level, joint commitment from relevant authorities in health and criminal justice; additional resources and a longer timeframe. 


\section{INTRODUCTION}

In England and Wales smoking rates among prisoners are nearly four times higher than in the general population at around 80\% [1-4], a level comparable with other countries [5-11]. Similarly high prevalence have also been found in police custody and probation [12,13]. Offenders are predominantly from more disadvantaged backgrounds and, together with their families, represent one of the most socially excluded groups, experiencing considerable health needs compared to the general population [14,15]. Offenders' problems are often complex and interrelated as many have poor life and coping skills and have also experienced long term disengagement from services (including health) and a lack of education, training and employment. Importantly, the prison setting is both a home for offenders and a workplace for staff and external service providers. Addressing tobacco control issues in prisons and wider criminal justice settings represents a major opportunity to engage with those normally considered 'hard to reach'. This has had increasing policy recognition $[16,17]$ and offers additional positive benefits in addressing wider health inequalities.

Offenders are a transient population and the 'offender pathway' within criminal justice settings (CJS) incorporates many organisational structures, including police custody, courts, prisons (often with movement between institutions) and probation services, as well as numerous community based health and social care agencies. In addition, many offenders have short sentences of six to twelve weeks, resulting in little time to initiate cessation support in the prison setting. Consequently, stop smoking support for offenders requires joined up working across CJS to raise the issue and encourage access to specialist and/or generic services, together with initiation of appropriate treatment and support. Adopting a whole systems approach [18] and addressing 'infrastructure deficits' [19] will enhance effectiveness of such initiatives and have the potential to extend their reach to other target groups including prison staff and offenders' families. The development of a tobacco coordinator role with scope to work across these systems represents an innovative approach to addressing these deficits and to promote joined up planning. 


\section{The Approach}

The organisational structures of prisons and the wider criminal justice system are diverse and require a holistic, multifaceted and multidisciplinary approach to support health-related behaviour change such as stopping smoking $[18,19]$. These requirements are conceptualised in the settings approach, which was recognised in the World Health Organization's (WHO) 'Health for All' strategy [20] and the subsequent Ottawa Charter for Health Promotion [21]. WHO define settings for health as "the place or social context in which people engage in daily activities and in which environmental, organizational and personal factors interact to affect health and wellbeing" (cited in [22]). However, whilst the value of holistic approaches to promoting health has been widely recognised, this tends to be inconsistently reflected in institutional structures, organisational decision-making and policy actions which often fail to address complex interrelationships among sectors $[18,19]$.

Prisons have been the major focus of development of health promotion and smoking cessation within CJS in England and Wales. Following the transfer of commissioning responsibility for prisoner health to the National Health Service (NHS) in 1995, health care provision, of which stop smoking services are a part, requires prisoners to have access to the same range and quality of health care services as the public receives in the wider community [23]. Opportunities and requirements for integrating approaches to health promotion in prisons were highlighted in 2002 in the strategy 'Health Promoting Prisons' which advocated for a whole prison approach. This was subsequently incorporated into the Prison Service Order 3200 (Health Promotion) in 2003, where smoking was identified as one of five areas for action $[24,25]$. In this way the Prison Service in the UK aims to meet its duty of care for those it detains, which covers the promotion and support of cessation, as well as protecting prisoners, staff and visitors from exposure to second-hand smoke. At the time of this project, stop smoking support delivered in prison settings, was typically commissioned by primary care trusts (PCTs), either through specialists going into the prison or through prison health care staff trained and supported by community stop smoking services. These arrangements have 
shown some successes, with four week quit rates higher in prisons than for any other setting apart from military bases (55\%: 2010-2011) [26]. However, numbers are small relative to the throughput of prisoners (132,000 in 2010 [27]) and therefore there is significant scope for improvement.

Looking beyond prisons, a recent Delivery Plan (2009) 'Improving Health, Supporting Justice’ [16] advocates for greater integration to improve the health and well-being of all those in contact with CJS, through, for example, the development of more effective pathways and improved signposting. The report identifies smoking as a risk behaviour worthy of attention. However, there are complex issues in play in each of the major settings, notably the often conflicting perceptions of punitive priorities and the need to support reparation and rehabilitation [28]. For example, prisons exist to punish criminals, separate them from society, correct and in due course rehabilitate them into the community [29]. In this environment, issues of health and well-being are often a lower priority. $[30,31,32,33]$. Similarly, probation services focus on reducing reoffending, with mental health, substance misuse and employment taking greater prominence over smoking cessation. However, it can be argued that successfully quitting provides many benefits in addition to improved health, such as improved self-worth; making positive steps towards improving quality of life and planning for the future.

A coordinator role offers an innovative approach to providing stop smoking support in an integrated way across CJS. Tobacco Control Coordinator posts have until recently, been in place in most English regions and with local services. However, a focus on broader CJS represents a new approach to embedding and sustaining change. Literature is sparse on the role and its value; studies are reported in other health settings such as long-term care for the elderly [34], school health [35] and mental health care [36], but despite promising outcomes, supporting evidence on impact and effectiveness is limited [34,35]. This project adapted best practice guidance for effective community engagement [37], which aims to promote health improvement in the NHS and other sectors using area-based 
partnership and coordination activities. The approach adopted a model of practical, experiential learning and knowledge transfer within the intervention settings.

\section{The Intervention}

The intervention was established to examine the opportunities of employing a tobacco control coordinator to work across a challenging and complex system, with a focus on improving continuity of care and equity of access to stop smoking services in prisons, probation and police custody. The North West region of England provided opportunities for learning across a range of organisational structures and commissioner-provider models. It incorporated 16 prisons, representing the full range of prisoner categories, five probation trusts, five police constabularies, 24 PCTs and various local government departments, with both urban and rural geographies. The intervention period ran for 12 months from December 2010.

The post was hosted by the University of Central Lancashire, in a unit which had expertise in healthy settings research and development in the criminal justice sector and established links with the local Regional Offender Health Team; local non-governmental organisations (NGOs) responsible for smokefree policies and supporting cessation, and PCTs across the region. The intervention manager was prisons and criminal justice programme lead for the Healthy Settings Unit and School of Health within the University and had established links with key stakeholders in the intervention area. A project advisory group (PAG) was established which incorporated representation from regional and national stakeholders in offender health and tobacco control. In addition, the coordinator worked within existing resources available in partner organisations. The project budget covered staff costs for a full-time coordinator and part-time administrative support, as well as costs for travel, IT and hosting local networking events. 
The coordinator role was not determined in advance, but evolved based on assessment of need and a responsive approach to opportunities that emerged to support stop smoking service delivery. It did not provide services to offenders directly but instead supported those organisations responsible for offender welfare. Chronologically the project moved from initial information gathering and identification of needs, towards agenda setting, in conjunction with project advisors, and developing and disseminating project outputs designed to address identified need (see Figure 1).

\section{FIGURE 1 ABOUT HERE}

The overall role comprised several interlinked activities, which can be described under two broad approaches. Firstly, enabling strategies and activities such as networking and partnership working were used to underpin the project's work. These included establishing links and identifying opportunities; acting as a stimulus for change and supporting wider dissemination of project learning. Secondly, a series of concrete outputs were developed. These included setting-specific case studies to promote aspects of good practice and share learning; guidance documents to encourage consistency in data monitoring and cessation service delivery, and a stop smoking training framework for criminal justice settings to support local training initiatives. Networking activities were a crucial feature of the intervention. The coordinator established connections with key professionals working within, alongside and beyond CJS, and linked with established networks and groupings. This enabled the coordinator to identify local needs and opportunities and ensured the project was well positioned to effect change.

\section{METHODS}

Evaluating programmes which are non-prescriptive and which result in unpredictable and diverse outcomes require a similarly adaptive approach [38]. Consequently, more prescriptive evaluation approaches such as randomised control trials have limited relevance to the many processes used in 
health promotion programmes and are often impossible to set-up in 'real world' situations [39]. In view of this, a mixed methods case study approach was used to examine the coordinator role and contributions, and to identify barriers and facilitators to project delivery.

In-depth qualitative interviews, the primary data collection method, were conducted using purposive sampling to obtain the perspectives of key stakeholders and intervention agents on programme delivery. These interviews were undertaken with the coordinator (five bi-monthly interviews); members of the advisory group (two interviews with five members at the beginning and end of the delivery period) and professionals representing a range of positions across the criminal justice and local public sectors who were either recipients of, or involved in the development of, project work (19 in total, conducted in the latter stages of delivery). Table 1 gives details of sample characteristics.

\section{TABLE 1 ABOUT HERE}

Respondents were approached by the research team to invite participation and obtain written consent. Initial interviews were guided by topic guides designed for specific interview groups, which were adapted as interviewing progressed and new themes emerged. Interviews with the coordinator focused on project activities and experiences of opportunities and challenges in delivering the project. Interviews with advisory group members and other professionals explored their experiences of the project and perspectives on its operation.

Secondary evaluation methods included on-going review and monitoring of monthly project reports and observation of PAG meetings. Two smaller scale evaluations, incorporating interviews and analysis of evaluation questionnaires, were undertaken to assess responses to a one-day conference and two training sessions organised and delivered as part of the project. 
All interviews were digitally-recorded with respondents' permission and were transcribed in full, with identifying details of respondents anonymised. Analysis themes were identified relating to the study aims and additional emergent areas of inquiry. As the analysis progressed, reliability of themes was established via cross-examination between investigators. This allowed areas of interpretative disagreement to be identified and addressed through redefinition of key concepts. The analysis was supported by Nvivo software. Analysis of the interview data was supplemented by reviewing project documentation and monitoring reports. Quantitative data relating to response to, and reach of the one-day conference and pilot training events were analysed descriptively, supported by Excel and SPSS.

\section{RESULTS}

Analysis of stakeholder narratives revealed a range of factors which influenced the progress of the project and its ability to engage and support local stakeholders from across criminal justice and primary care. These factors were grouped under four broad themes, each of which acted as both barriers and enablers to project delivery. The themes covered internal factors such as programme design and implementation, over which the project had direct control, as well as external factors which related to the intervention settings and wider environmental influences.

\section{Implementation Factors}

The experience, skills and personality of the coordinator emerged as critical factors influencing implementation, reflecting the dependence on a single individual to implement the intervention. In particular, the post-holder's networking skills acquired through previous health coordinator positions, coupled with his ability to exploit existing links with local public health communities were important enabling factors. 
"He's able to understand, you know, the public health issues that are involved and really sort of approach it from a patient perspective as well, and to evaluate what would be practical and not practical."

"It could have been very different had we recruited somebody who didn't have the networking skills that [the Coordinator] has got, or that didn't have the ability to access the networks that he's got."

These qualities were regarded as critical assets which enabled the project to progress more rapidly and to establish a wider network of support than might otherwise have been possible. Nevertheless, some skills gaps and linkages were judged to act as limiting factors. Most specifically, the postholder's lack of experience in the field of tobacco control and limited links with parts of the criminal justice system, which were addressed by additional programme support from the intervention manager and project advisors.

\section{Programme Factors}

Three programme elements emerged as factors influencing delivery: management support, hosting arrangements and length of delivery period.

The existence of established links with, and strong understanding of, local criminal justice and primary care structures by the intervention manager and members of the advisory group, had an important influence on the reach and scope of the project. These links were important to facilitating access to relevant institutions and bodies, and were responsible for initiating much of the development work undertaken within the prisons community and establishing advocates and training partnerships in the probation sector. 
"Because of [the intervention manager's] work we had a fairly extensive list of contacts for the prisons in terms of health care leads so the starting point was really quite simple. So the prison's bit has been really quite easy."

Conversely, in those areas of the system where links with the project were absent or less well developed, the coordinator typically struggled to have an influence.

The choice of host institution, a health research unit located within a local university, also had an impact on how the project was perceived and the way in which stakeholders engaged with it. Keeping the project organisationally separate from the criminal justice system was considered to give it the independence to respond flexibly and the ability to work across the range of stakeholder agendas necessary to the coordinator role

"Because [the Coordinator's] not employed by health, not employed by the prison service, the constraints are completely different. There is more flexibility there."

"I think it helped being based within a University - it helped to give credibility and kept it separate from day to day business."

However, there was no clear consensus on the ideal location. Some stakeholders were ambivalent about the hosting arrangements, while others, particularly those in the prison sector, expressed unease about engaging in an initiative that, by virtue of its location, could be seen as part of a research project.

"People can get a little twitchy about participating in [what can be seen as] research." 
Finally, the prescribed delivery period of 12 months was widely considered insufficient for a coordination role working at a regional level across both health and criminal justice. As a consequence the project initially prioritised those areas where it was likely to have greatest impact within the time available, and subsequently worked with those institutions who expressed a willingness to engage, although there was insufficient time to embed individual advances made.

"I am not feasibly going to be able to work in a twelve month period with all the people across the system and engage them all to the same level. What I can do is pick out those that (1) show interest (2) that are in a reasonable position to be able to progress some of what we are saying we want to do, but again that's a coordination role."

Similarly, the project outputs developed to share good practice and support consistency in delivery were not fully utilised during the project lifetime, although the relevant documents were made available on the project website.

\section{Settings-related Factors}

Given the project's dependence on working with existing resources available within the wider system, engagement with the project by the various criminal justice settings varied in accordance with their readiness to change and the extent to which tobacco control formed part of local operational agendas. These different patterns of response are illustrated by three settings-specific case studies (BOX 1-3), which describe the engagement strategies adopted and the types of impacts achieved in each setting, alongside practice learning to emerge from these experiences and implications for future development. 
Prisons were described as 'the easy bit of the jigsaw' and emerged as the setting most prepared to engage with the project. This was largely attributed to the fact that there was a statutory requirement to provide cessation support within prisons. Consequently, relatively low level intervention work which raised awareness of service issues and in some cases brought together local stakeholders, was sufficient to act as an impetus for change.

"In prison it is about making sure that the services that are being delivered are robust enough and are being delivered in the way that they should be. That feels easier, although it's still a big challenge."

“.....we've had very little input into [named prison] other than the initial review ...And again I think it's just that issue about putting a bit of a spotlight on it and somebody's started asking questions, they've looked at what they could do..."

\section{BOX 1 HERE}

In contrast, in probation where formal commissioning arrangements were not an operational requirement, the focus was placed on promoting brief intervention training and documenting and sharing examples of good practice as ways of influencing the wider social and health care agenda .

"From probation's point of view, when they come out on supervision, they haven't really looked at the issues of smoking, because they've got other priorities like trying to prevent reoffending and drugs, alcohol, mental health, employment..."

BOX 2 HERE 
Engagement challenges were greatest in the police custody setting because tobacco control issues rarely featured on the custody health and safety agenda, and there was a lack of capacity and will to deal with the issue. As a consequence, the aim here was limited to using existing networks and links to try and encourage discussion of nicotine replacement therapy (NRT) provision at the regional police custody forum. These efforts were hampered by the apparent absence of national guidelines on the provision of NRT in police custody. Experience suggests the project did not have the necessary profile and resources to effect change at the level required in this setting.

"With custody we haven't spent as much time perhaps on it largely because it's just been brick wall stuff."

"The Regional Custody Forum seems to be the intervention point, the right level, but maybe the project hasn't got the recognition and the credibility to do it at that level...."

BOX 3 HERE

On reviewing the different levels of engagement achieved in each setting it was widely speculated that a higher level strategic approach was required if the project was to effect change at an organisational level and establish wider partnership working across the system.

"I think we need to engage more strategically, I think the future would be to do that. I think what this project has done [so far] is established ways of doing things on the ground." 
It was also suggested that operating at a higher strategic level was more consistent with a regional post which required the commitment of a relatively large number of institutions and agencies from across a range of settings.

\section{Environmental Factors}

Two environmental factors acted as significant barriers at the time of delivery. These were the economic down-turn which placed constraints on public finances, and organisational changes to national health services, especially primary care, which were responsible for uncertainties about future commissioning arrangements for stop smoking services.

"We are undergoing audits of where our time can be most effectively spent so I think until that is done I don't think training [for brief interventions] is high on the agenda for us at the moment because we've got bigger priorities."

"It depends on what happens with the commissioning of prison health care generally because the talk is that it's going to be part of the national commissioning board, so it depends on what the roles are..."

These wider environmental factors and the transitional context not only had an impact on the structures and networks on which the project relied, but also on the management team and individual implementers, through organisational funding cuts, changing job remits and delays on decisions to fill vacant posts. However, it was also speculated that the proposed structural changes could in time open up new development opportunities.

\section{DISCUSSION}


The diverse nature of CJS and commissioner-provider models in the intervention area offered an ideal opportunity to examine barriers and facilitators to a tobacco control coordinator working at a regional level across the criminal justice sector. Despite a difficult operational climate characterised by financial cutbacks and organisational restructuring, the project was able to demonstrate progress in a number of areas, and plans to embed public health within local authority structures [42] may offer new opportunities to address stop smoking provision as part of a wider health and social inequalities agenda.

Of particular relevance is the differential reach and impact the role appears to have in each of the three criminal justice settings addressed by the project. This has implications for where in the system and management hierarchy the coordinator is located and the level of resourcing needed to support the role. As illustrated by the setting-specific cases studies, the requirement to work within existing resources means that developments were mainly restricted to the prison setting where tobacco control measures were already an established feature of the offender health service landscape and where the coordinator role was able to act as a catalyst for change and improvement. It might be reasonable to speculate that the general uncertainty across the system which prevailed at the time may in part account for the lack of progress made in the other criminal justice settings, particularly police custody, where the absence of clear national guidance is also a constraining factor.

This divergence in readiness to engage with the tobacco control agenda and provision of stop smoking support creates challenges for developing joint planning initiatives and identifying offender care pathways across CJS. Current government proposals for a national commissioning board may provide a platform for a more coherent approach to commissioning for offender health [43]. In addition, given these differentials, developing complementary strategies for working with the different criminal justice agendas in each setting suggests there may be value in positioning support 
to reflect differing local priorities. For example, in the probation setting, promoting stop smoking support to those released under license into the community as a means of reducing reoffending through boosting self-esteem, and in the police custody setting, providing NRT as a means of addressing nicotine withdrawal and related feelings of aggression and stress.

Learning suggests that reach and impact could be enhanced by extending the role to operate at a strategic level, to facilitate partnership working across health and criminal justice systems. Such an extension away from a reliance on the needs-led approach adopted here has the potential to enhance the role's influence through the formation of a regional tobacco control strategy. The success of incorporating a systems-level, strategic partnership approach is likely to depend upon a number of factors, including a requirement for a higher level appointment; additional resources; a joint commitment from relevant authorities in health and criminal justice; establishing national policy drivers and a longer time frame to negotiate and implement an agreed strategy.

In conclusion, this relatively modest intervention study provides some useful insights into the value and development potential for a tobacco control coordinator role working across CJS to improve provision of cessation support. These initial results suggest the approach provides a promising mechanism for targeting disadvantaged offender populations for whom smoking is the norm and who are often missed by conventional services. In this way it could have significant public health benefits in helping to narrow the gap in health inequalities. At a broader level the study findings further establish the evidence base regarding the benefits and limitations of a coordinator role and its contribution to health improvement.

\section{Limitations}

The study was designed to examine delivery processes associated with the coordinator role, working across relevant systems and localities rather than within specific pilot sites. Through these 
observations and stakeholder accounts the evaluation was able to illustrate some of the short term impacts of the project on developing practice and to identify factors influencing project delivery. However, the evaluation was not designed to assess the impact of the project at an individual level on, for example, client reach, numbers quitting and using stop smoking services, and related cost effectiveness; nor was it designed to assess long term impact on health outcomes. Indeed, the absence of reliable systems for collecting routine data was identified as a key development area by the project, although the extent to which these and other areas could be fully addressed during the life of the project underline limitations in terms of time and scope.

There are also a number of features of the project model which make direct replication of the intervention difficult and indeed undesirable. Project delivery was dependent upon two inter-related features which can display considerable variance: a reliance on a relatively autonomous actor, the coordinator, to guide the project work, and his or her ability to engage the various structures, networks and people in place in order to facilitate change. In this way, an approach which involves responding to local need does by definition require the development of different and in some cases unique solutions to improving service delivery. Indeed it is this type of creative response that is a potential strength of the approach, in effect identifying novel approaches to addressing structural barriers to change. In view of this, the challenge to extending this aspect of the coordinator role to other areas is not simply one of replication, but is rather an adaptive process that needs to be sensitive to local need, and which requires complementary support structures and forums which enable those tasked to perform the role to share experiences, learning and new ways of working, and through this process of sharing, to identify innovation and promising areas of practice deserving of more detailed study. 


\section{ACKNOWLEDGMENTS}

The project is part of a portfolio funded by the Department of Health and led by the UK Centre for Tobacco Control Studies (UKCTCS: www.ukctcs.org). Stephen Woods, the Project Coordinator, had a central role in delivering the project which forms the focus of this evaluation. He also produced the initial draft case studies, under the direction of the intervention manager. The authors would like to acknowledge the support of the National Offender Management Service's North West office; the Regional Offender Health Team; the Governance Teams; prisons, particularly those participating in the case studies; Greater Manchester Probation Trust; NHS Heywood, Middleton and Rochdale PCT; Tobacco Free Futures and many other participating agencies. Thanks also to Debbie Cocker and Aileen Paton who provided administrative support. 


\section{REFERENCES}

1. Plugge E.H., Foster C.E., Yudkin P.L., Douglas N.. Cardiovascular disease risk factors and women prisoners in the UK: the impact of imprisonment. Health Promotion International 2009; 24: 334-343.

2. Cropsey K.L., Crews K.M., Silbermen S.L. Relationship between smoking and oral health in a prison population. Journal of Correctional Healthcare 2005; 12: 240-248.

3. Cropsey K.L., Eldridge G., Weaver M.F., Villalobos G.C., Stitzer M.L. Expired carbon monoxide levels in self-reported smokers and non-smokers in prison. Nicotine and Tobacco Research 2005; 8: 653-659.

4. Cropsey K.L., Jones-Whaley S., Jackson D.O., Hale G.J. Smoking characteristics of community corrections clients. Nicotine \& Tobacco Research 2010; 12: 53-58.

5. Hartwig C., Stöver H., Weilandt C. Report on tobacco smoking in prison: Final Report Work Package 7. Directorate General for Health and Consumer Affairs (DG SANCO). DG SANCO/2006/C4/02; 2008.

6. Belcher J.M., Butler T., Richmond R.L., Wodak A., Wilhelm K. Smoking and its correlates in an Australian prisoner population. Drug and Alcohol Review 2006; 25: 343-348.

7. Sieminska A., Jassem E., Konopa K. Prisoners' attitudes towards cigarette smoking and smoking cessation: A questionnaire study in Poland. BMC Public Health 2006; 6.

8. Nijhawan A.E., Salloway R., Nunn A.S., Poshkus M., Clarke J.G. Preventive Healthcare for Underserved Women: Results of a Prison Survey. Journal of Women's Health 2010; 19: 17-22.

9. Holmwood C., Marriott M., Humeniuk R. Substance use patterns in newly admitted male and female South Australian prisoners using the WHO-ASSIST (Alcohol, Smoking and Substance Involvement Screening Test). International Journal of Prisoner Health 2008; 4: 198-207.

10. Papadodima S.A., Sakelliadis E.I., Sergentanis T.N., Giotakos O., Sergentanis I.N., Spiliopoulou C.A. Smoking in prison: a hierarchical approach at the crossroad of personality and childhood events. European Journal of Public Health 2010; 20: 470-474. 
11. Scottish Prison Service. Prisoner Survey 2009. Available at: http://www.sps.gov.uk/MultimediaGallery/e7698343-107e-48c9-90ce-80db7698b5b3.pdf (accessed 9 August 2010); 2010.

12. Payne-James J.J., Green P.G., Green N., McLachlan G.M.C., Munro M.H.W.M., Moore T.C.B. Healthcare issues of detainees in police custody in London, UK. Journal of Forensic and Legal Medicine 2010; 17: 11-17.

13. Brooker C., Fox C., Barrett P., Syson-Nibbs L. A Health Needs Assessment of Offenders on Probation Caseloads in Nottinghamshire \& Derbyshire: Report of a Pilot Study. Lincoln: CCAWI University of Lincoln. Available at: http://www.nacro.org.uk/data/files/nacro-2008071500176.pdf (accessed 22 April 2010); 2008.

14. Social Exclusion Unit. Reducing reoffending by ex-prisoners. London: Social Exclusion Unit; 2002.

15. National Offender Management Service (NOMS) \& Home Office. National Reducing Reoffending Action Plan. London: Home Office Communications Directorate; 2004.

16. Department of Health. Improving Health, Supporting Justice. London: Department of Health; 2009

17. Department of Health. A Smokefree Future: A Comprehensive Tobacco Control Strategy for England. London: Department of Health; 2010.

18. Dooris M. Holistic and sustainable health improvement: The contribution of the settings-based approach to health promotion. Perspectives in Public Health 2009; 129(1): 29-36.

19. Ziglio E., Hagard S., Griffiths J. Health promotion development in Europe: Achievements and challenges. Health Promotion International 2000; 15(2): 143-154.

20. World Health Organization. Health for All. Geneva: WHO; 1980.

21. World Health Organization. Ottawa Charter for Health Promotion. Geneva: WHO; 1986.

22. Dooris M. Healthy settings: challenges to generating evidence of effectiveness. Health Promotion International 2006; 21: 55-65. 
23. Department of Health. The Future Organisation of Prison Healthcare. London: Department of Health; 1999.

24. H.M. Prison Service (HMPS). Prison Service Order (PSO) 3200 on Health Promotion. London: HM Prison Service; 2003.

25. Department of Health. Health Promoting Prisons: A Shared Approach. London: Department of Health; 2002.

26. NHS Information Centre, Lifestyles Statistics. Statistics on NHS Stop Smoking Services: England, April 2010 - March 2011. Available at:

http://www.ic.nhs.uk/webfiles/publications/003 Health Lifestyles/NHS\%20Stop\%20Smoking \%20Services\%20201011/SSS 2010 11.pdf; 2011.

27. Ministry of Justice. Prison Population Projections 2011-2017 England and Wales. London: Ministry of Justice; 2011. Available at:

http://www.justice.gov.uk/downloads/statistics/mojstats/prison-pop-projections-2011-17.pdf

28. Baybutt M., Hayton P., Dooris M. Prisons in England and Wales: An important public health opportunity? Chapter in Douglas J., Earle S., Handsley S.S., Lloyd C., Spurr S. (eds.), A Reader in Promoting Public Health: Challenge and Controversy. London: Sage/Milton Keynes: Open University Press; 2006.

29. Watson R., Stimpson A., Hostick T. Prison health care: A review of the literature. International Journal of Nursing Studies 2004; 41: 119-128.

30. Birmingham L. Prison medicine: Ethics and equivalence. The British Journal of Psychiatry 2006; 188: 4-6.

31. Scott D., Codd H. Controversial Issues in Prisons. Berkshire: Open University Press; 2010.

32. de Viggiani N. Unhealthy prisons: Exploring structural determinants of prison health. Sociology of Health \& Illness 2007; 29(1): 115-135.

33. Howard League for Penal Reform. Prisons are Incapacitated by Overcrowding. Press release 11 March 2005. 
34. Pronych G.J., Brown E.J., Horsch K., Mercer K. Oral health coordinators in long-term care - a pilot study. Spec Care Dentist 2010; 30: 59-65.

35. O’Brien L.M., Polacsek M., MacDonald P.B., Ellis J., Berry S., Martin M. Impact of a school health coordinator intervention on health-related school policies and student behavior. J Sch Health 2010; 80: 176-85.

36. Halperin G., Boz-Mizrahi T. The Amitim program: an innovative program for the social rehabilitation of people with mental illness in the community. Isr J Psychiatry Relat Sci 2009; 46: 149-56.

37. National Institute for Health and Clinical Excellence (NICE). Community Engagement. NICE Public Health Guidance 9; 2008.

38. Stead M., Hastings G., Eadie D. The challenge of evaluating complex interventions: A framework for evaluating media advocacy. Health Education Research 2002; 17(3): 351-364.

39. Allison K.R., Rootman I. Scientific rigor and community participation in health promotion research: are they compatible? Health Promotion International 1996; 11(4): 333-334.

40. H.M. Inspectorate of Prisons and H.M. Inspectorate of Constabulary (HMIC). 'Expectations for Police Custody'. Criteria for assessing the treatment and conditions for detainees in police custody. London: Criminal Justice Joint Inspection; 2009.

41. Faculty of Forensic and Legal Medicine (FFLM). Policy Statement Nicotine dependent detainees in Police custody - faculty view. Available at: www.fflm.ac.uk (accessed August 2011); 2008.

42. HM Government. Healthy Lives, Healthy People: Update and Way Forward. London: The Stationary Office; 2011.

43. Department of Health. The Role of the NHS Commissioning Board. Available at: http://healthandcare.dh.gov.uk/the-role-of-the-nhs-commissioning-board/; 2011. 
Table 1: Sample Characteristics

\begin{tabular}{|l|c|c|}
\hline Occupational Background & No. of Respondents & No. of Interviews \\
\hline Probation Service & 2 & 2 \\
\hline Prison Healthcare & 5 & 5 \\
\hline PCT Public Health & 3 & 3 \\
\hline Stop Smoking Services - NHS and Voluntary & 1 & 1 \\
\hline Pharmaceutical Industry & 3 & 3 \\
\hline Youth Offending Team & 1 & 1 \\
\hline Alcohol and Drug Action Team & 1 & 1 \\
\hline Police & 5 & 10 \\
\hline PAG members & 1 & 5 \\
\hline Coordinator & $\mathbf{2 5}$ & $\mathbf{3 4}$ \\
\hline Total & & \\
\hline
\end{tabular}




\section{Resources}

- Full-time co-ordinator

- Intervention manager

- Expert advisors

- Administrative support

- Travel, IT and events budgets

\section{Enabling strategies} and activities

- Networking

- Partnership working

- Information sharing

- Needs assessment

- Training
Phase 1: Information gathering and identifying local needs

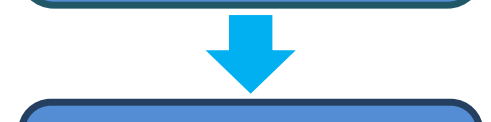

Phase 2:

Setting the project agenda
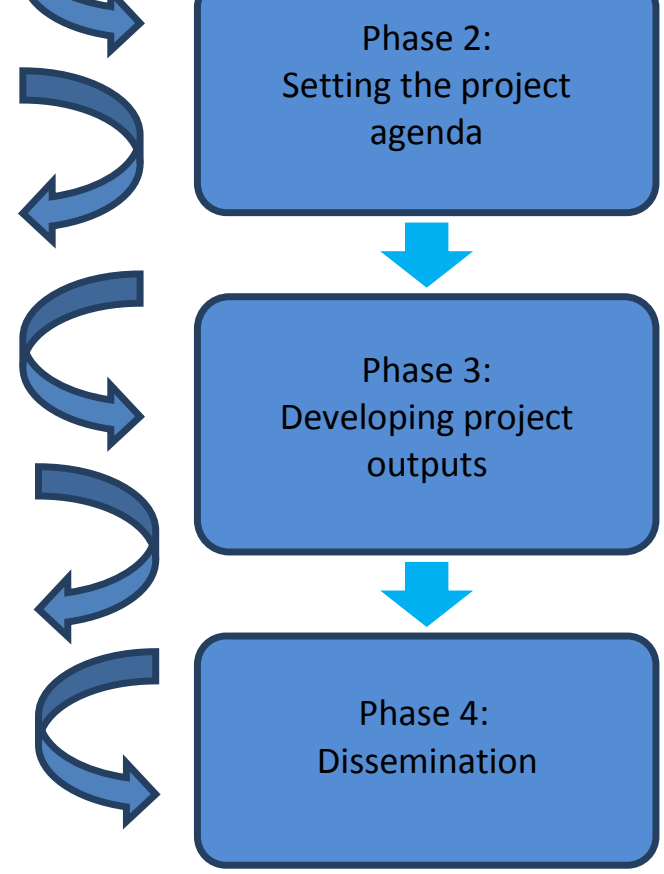

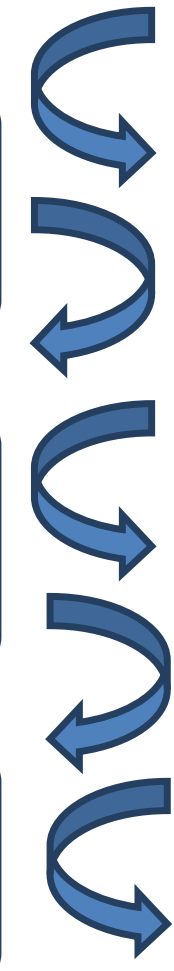

\section{Communication} tools

- Networking events

- Bi-monthly e-newsletter

- Project website

- Stakeholder database

\section{Coordinator legacies}

- Enhanced cessation delivery in some settings

- Improved relationships and connectivity across organisations of varying intensity

- Improved understanding and awareness of tobacco control issues

- Expanded networks and forums

\section{Outputs}

- Data monitoring and service delivery guidance documents

- Settings based training framework

- Settings-specific case studies 
BOX 1 Service Development in a Prison

\section{Context}

The prison is a large women's prison with accommodation largely in detached houses and a mother and baby unit which is smokefree. Smoking cessation support was offered but numbers were negligible at the time of the first coordinator visit. The case study provides an illustration of how a 'light touch' approach, as part of the coordinator role, can facilitate positive change.

\section{Intervention}

As part of the mapping review exercise, it was highlighted that whilst group quit programmes were provided in principle, several factors had contributed to a downturn in provision:

- Staff capacity issues and lack of trained staff.

- Variable allocation of clinic rooms and session times.

- Regime issues restricting prisoner movement to sessions.

- Rapid turnaround of some prisoner categories as prisoners moved between and from prison.

- No additional incentives to quit offered and no involvement of prisoners in service provision.

- No support for staff to stop smoking.

Following the initial mapping review there were a number of positive developments. Notably a multi-agency development meeting was convened by the coordinator with leads from the prison, public health, commissioning and the community stop smoking team to explore service delivery issues. This recognised past challenges, recent developments and addressed future needs and opportunities.

The initial mapping work and subsequent intervention by the coordinator as a resource, acted as a 
catalyst for change resulting in increased attendance at sessions and successful four week quits.

Access to clinics increased steadily from 12 clinic slots in January 2011, to 104 clinic slots in May

2011, levelling off thereafter. Numbers setting a quit date also increased from zero in January 2011

to 16 in May 2011. Numbers of four week quitters remained low however, with only one or zero per month up to June 2011 when there were three successful quitters.

\section{Practice Learning}

A number of factors appeared to improve engagement and quit levels:

- Addressing capacity issues by provision of advisor training for health care and integrated drug treatment service staff through community stop smoking services.

- Changing from group to 1:1 support appeared more manageable and counteracted the less productive 'sociable' motivation for engagement.

- Establishing regular clinic sessions and room allocations facilitated appointment systems, which were preferable to 'drop in'.

- Provision of NRT on the first visit, following assessment, addressed short stay issues.

- Discussions with discipline staff about movement issues enhanced attendance levels.

- Use of Quit Manager (as used by community services) facilitated more accurate data collection and monitoring, and local connection on discharge.

- Personal appointment cards improved clarity and facilitated on-going support on transfer or release.

- Highlighting services at the second health screen rather than on prison entry enabled more balanced consideration by inmates and hence fewer women who did not attend (DNAs).

Additional developments contributed to a more positive smoking cessation environment: for example, the prison's health promotion group became more active in working towards a healthy 
prison approach, and expansion of smokefree accommodation came under consideration.

Moreover, information on local services and, if appropriate, one week's supply of NRT was included in health promotion release packs.

\section{Recommendations for Developing Quit Services in Prisons}

- Foster partnership working between community stop smoking specialists, prison health care staff and commissioners, and across the prison environment, to maximise service effectiveness.

- Establish consistent structures to be integrated into staff rotas, clinic room allocations, inmate appointments and prison movements.

- Ensure sufficient staff are suitably trained to cover sessions.

- Review delivery approaches: 1:1 may be more suitable than group programmes, especially with high inmate turnover.

- Support development of smokefree living areas and consider additional incentives to reward quitting.

- Integrate second hand smoke awareness in parenting classes.

- Provide brief intervention training across prison staff to raise awareness and support engagement. 
BOX 2 Opportunities in Probation Settings

\section{Context}

The probation setting offers opportunities for the effective delivery of stop smoking services, alongside engaging people informally who are normally considered 'hard to reach' in a familiar environment. The primary driver for health interventions is the opportunity to tackle risk factors associated with reoffending. Consequently, mental health, substance misuse and employment assume a higher priority than smoking cessation. However, the project identified considerable potential to bridge the two aims of reducing re-offending and promoting positive health behaviour changes.

\section{Intervention}

The coordinator's initial task was to review the innovative Offender Health $\operatorname{Trainer}^{1}[\mathrm{OHT}]$ Project, located within a sub-regional probation service, in relation to the delivery of Stop Smoking Service provision. Key themes explored included:

- Training received to set up and deliver the OHT service, including smoking cessation.

- Interrogating available data.

- Partnership working.

- Client needs and aspirations relating more broadly across the OHT service.

- Reflecting on future service developments - for example, the need to link prisoners to the $\mathrm{OHT}$ service on release, utilising the probation induction programme to raise awareness and signpost ex-offenders.

This also led to reviewing related activity in two other probation settings: approved premises 
(formerly bail hostels) and a women's project. The coordinator approached this through informal telephone and face to face meetings $(n=8)$ with a range of stakeholders across health and justice agencies.

\section{Practice Learning}

There was considerable value in exploring how stop smoking support in probation settings might serve the wider agenda to reduce reoffending, improve service engagement and smoking quit levels through initiatives such as the:

- Offender Health Trainer Project that used the principles of peer education to promote health behaviour change. Research suggests that making these kinds of changes can contribute to improved self-esteem, self-worth and increased confidence levels which could act as drivers to reduce reoffending behaviour.

- The women's project which supports and encourages women who may be at risk of offending to develop an individual work plan. Smoking is included as part of the health check.

In turn, the coordinator was able to demonstrate:

- Opportunities for developing and effective location of stop smoking service delivery.

- Good practice initiatives.

- Key learning to replicate and join up across the system.

Training was identified as key in terms of improving and changing knowledge, attitudes and practice in order to deliver an effective service. In addition, locating stop smoking services within approved premises [formerly bail hostels] provides an engagement opportunity as the setting is well placed to deliver structured group or 1:1 interventions for offenders subject to curfew. 


\section{Recommendations for Developing Quit Services for Offenders in Probation Settings}

- Support early referral of quitters to an offender health trainer on release from prison to help reduce the potential for relapse: consider links being made prior to release.

- Develop offender health trainers as stop smoking advisors in order to provide more immediate access to support and treatment governed by community stop smoking teams.

- Foster partnership working between community stop smoking specialists, probation, prisons, health service commissioners and wider community agencies to maximise effectiveness of stop smoking services.

- Explore opportunities for delivering targeted stop smoking interventions in approved premises: as a minimum, establish access to information, protocols and clear pathways into services.

- Pilot the delivery of stop smoking brief intervention training programme to project staff.

- Incorporate support in relation to the impact of second hand smoke on children into training where appropriate.

1. Offender health trainer programmes are based on longer established community health trainer programmes; namely trained peers offering one-to-one support, to help identify and make positive health changes and to encourage engagement with other services. 


\section{BOX 3 Promoting NRT Provision in Police Custody Suites}

\section{Context}

Police custody is the first stage of the offender journey following arrest or detention. Stays typically last 6-8 hours and the setting is not exempt from smokefree legislation. This has significant implications for managing the effects of nicotine withdrawal; especially given smoking prevalence is similar to other criminal justice settings. Custody suites are therefore well positioned to support enforced abstinence and to act as a gateway to stop smoking and other healthcare services [16].

\section{Intervention}

The project aimed to promote the provision of NRT in police custody suites across the intervention area. Initially, the coordinator conducted a search for relevant national policies and a country-wide review of police custody smoking policies available online $(n=20)$, followed by a fact finding exercise with a senior police officer to assess existing practice and to explore the potential for establishing local alliances.

The reviews provided useful examples of area smoking policies and NRT and some general indicators of national policy. However, support from local constabularies to raise the issue at the region's police custody forum was not forthcoming as tobacco control was widely regarded as a low priority area. This led to further efforts to gain a voice at the forum through senior public health executives and to work with the regional offender health team to review new police custody health care contracts. Whilst the impact of these efforts was limited, the project did succeed in influencing routine collection of detainee smoking data as part of a local health pilot. 


\section{Practice Learning}

Despite the limited progress made by the project in this setting, a number of useful learning points emerged:

- Custody suites are not considered conducive to delivering cessation support as detainees are often in crisis and there is limited capacity for structured intervention.

- A minority of smoking policies permit detainees to smoke in 'exceptional circumstances' in exercise yards and custody cells.

- Current local variability highlights scope to explore routine provision of NRT both to counteract nicotine withdrawal and to motivate detainees to consider stopping. Routine assessment of detainees for risk of harm provides an ideal opportunity to screen for smoking.

- Nationally, there does not appear to be a requirement to provide pharmacotherapies. However, the 'Expectations Criteria' for assessing health provision requires inspectors to routinely assess availability of NRT [40] and the Faculty of Forensic and Legal Medicine [41] provides special grounds to support temporary abstinence.

- Positioning NRT provision as addressing the more severe effects of nicotine withdrawal such as depressive symptoms and aggression [40] is likely to be of greater relevance to police authorities than highlighting health benefits of quitting.

- Additional advantages of pharmacotherapies include avoidance of exposure to second-hand smoke by staff and other detainees, and reduced need for security measures such as handcuffing and escorting detainees to outside areas.

- Appropriate pharmacotherapies include micro tablets or mini lozenges because of rapid effect, ease of administration and lower security and choking risks.

- Information on local community stop smoking services should be provided to smokers. 


\section{Recommendations}

There is a need for greater clarity on national policy for the provision of pharmacotherapies in police custody that takes cognizance of smokefree environments and growing awareness of staff and detainee rights to be protected from second-hand smoke. There is an opportunity for the proposed national commissioning board to establish provision of NRT as a priority area as police forces review their health care contracts. There is also a need for pilot work to evaluate temporary abstinence supported by NRT as a trigger for a sustained quit attempt. 